\title{
HUBUNGAN NILAI DMF-T TERHADAP PRESTASI BELAJAR ANTARA SDN PAGEJUGAN 01 DENGAN SDN 03 BREBES DI KABUPATEN BREBES
}

\author{
Noviasari Nursasi $^{1}$, Salikun $^{\varpi^{2}}$, Bedjo Santoso $^{3}$, Supriyana $^{4}$
}

\begin{abstract}
ABSTRAK
Menurut Penelitian yang dilakukan oleh Pemerintah ( Riskesda) 2009 ada 89\% anak-anak Indonesia pada usia di bawah 12 tahun yang memiliki karies gigi. Rata-DMF-T derajat kesehatan gigi diperoleh dari kerusakan gigi, karena hilang dan dicabut yang disebabkan oleh karies gigi. Kondisi ini akan mempengaruhi kesehatan mereka, pertumbuhan dan prestasi belajar. Tujuan dari penelitian ini adalah untuk mengetahui hubungan DMF-T kelas untuk belajar prestasi antara SDN Pagejugan 01 Brebes dan SDN 03 Brebes.

Jenis penelitian ini adalah deskriptif kuantitatif dimana sampel diambil oleh Proporsional Stratified Random Sampling. Ada 209 sampel; 119 sampel di SDN 03 Brebes dan 90 sampel di SDN Pagejugan 01 Brebes. Data tersebut diambil dengan mengamati dan meneliti. Variabel bebas adalah nilai DMF-T dan variabel dependen adalah prestasi belajar.

Hasil dari penelitian ini adalah rata-rata DMF-T kelas SDN 03 Brebes adalah 0,7 yang memiliki kriteria terendah dan SDN Pagejugan 01 Brebes adalah 1,4 yang memiliki kriteria rendah. Rata-rata prestasi belajar SDN 03 Brebes adalah 76,78 yang memiliki kriteria yang baik dan SDN Pagejugan 01 Brebes adalah 68,46 yang memiliki kriteria yang cukup baik. Ini berarti bahwa SDN 03 Brebes cenderung ke arah ada hubungan DMF-T kelas untuk belajar prestasi dan SDN Pagejugan 01 Brebes cenderung tidak ada hubungannya dengan prestasi belajar. Peneliti saran adalah siswa harus merawat gigi dan mulut mereka dengan menyikat gigi secara teratur, guru dan orang tua harus mengontrol gigi anak-anak secara teratur dan mereka juga harus memperkenalkan cara merawat gigi dan mulut. Untuk penelitian, hal itu harus dilakukan dengan menggunakan kategori karies serius seperti pulpitis atau periodontitis.
\end{abstract}

Kata Kunci: skore DMF-T, Prestasi Belajar, Puskesmas Brebes I Kabupaten Brebes

\begin{abstract}
DMF-T score is the grade which is obtained from dental decay, missing and fiiled that caused by dental caries. 89\% Indonesian children at the age under 12 years, have dental caries. This condition will effect their health, growth and learning achievement. The aim of the research is to know the relation DMF-T grade to learning achievement between SDN Pagejugan 01 Brebes and SDN 03 Brebes.

The type of the research is descriptive quantitative where sample is taken by Proportionate Stratified Random Sampling. There are 209 samples; 119 samples in SDN 03 Brebes and 90 samples in SDN Pagejugan 01 Brebes. The data is taken by observing and examining. The independent variable is DMF-T score and dependent variable is learning achievement.

The result of the research is the average DMF-T grade of SDN 03 Brebes is 0,7 which has the lowest criteria and SDN Pagejugan 01 Brebes is 1,4 which has low criteria. The average of learning achievement SDN 03 Brebes is 76,78 which has good criteria and SDN Pagejugan 01 Brebes is 68,46 which has good enough criteria. It means that SDN 03 Brebes tends toward there is relation DMF-T grade to learning achievement and SDN Pagejugan 01 Brebes tends there is no relation to learning achievement. The researcher suggestion is the student should take care of their teeth and mouth by brushing their teeth regularly, teacher and parents should control children's teeth regularly and they also should introduce how to take care of teeth and mouth. For research, it should be done by using serious caries category like pulpitis or periodontitis.
\end{abstract}

Kew Words : DMF-T Score, Learning Achievement

${ }^{1)}$ Perawat Gigi Puskesmas Brebes I Kabupaten Brebes

${ }^{2,3,4)}$ Dosen Jurusan Keperawatan Gigi Poltekkes Kemenkes Semarang

$凶$ : salikun62@gmail.com 


\section{PENDAHULUAN}

Pembangunan kesehatan diarahkan untuk meningkatkan kesadaran, kemauan dan kemampuan hidup sehat bagi setiap orang agar peningkatan derajat kesehatan masyarakat yang setinggi-tingginya dapat terwujud (RPJPN, 2005). Usaha mewujudkan pembangunan di bidang kesehatan menuju Indonesia sehat 2010 yang bertujuan untuk meningkatkan derajat kesehatan masyarakat Indonesia salah satunya adalah pembangunan di bidang kesehatan gigi (Muhariani, 2008).

Program kesehatan gigi dan mulut pada hakekatnya ditunjukkan kepada seluruh masyarakat yang bertujuan untuk meningkatkan derajat kesehatan gigi dan mulut masyarakat itu sendiri (Depkes RI, 1982). Kelompok anak usia Sekolah Dasar (SD) adalah salah satu kelompok yang rentan terhadap penyakit gigi dan mulut. Hal ini disebabkan pada usia SD terdapat masa gigi bercampur dimana terdapat gigi susu maupun gigi tetap. Selain karena masa gigi bercampur kerentanan pada anak usia SD juga disebabkan karena pada usia ini terjadi proses pertumbuhan rahang yang sangat di pengaruhi oleh optimalisasi fungsi pengunyahan (Depkes RI, 1999).

Salah satu penyakit gigi dan mulut yang sering terjadi pada anak usia Sekolah Dasar adalah karies. Menurut penelitian di negara-negara Eropa, Amerika dan Asia, termasuk Indonesia, ternyata bahwa 80-95\% dari anak-anak di bawah umur 18 tahun terserang karies gigi (Tarigan, 1990). Selain itu Sebanyak $89 \%$ anak Indonesia di bawah 12 tahun menderita penyakit gigi dan mulut. Kondisi itu akan berpengaruh pada derajat kesehatan mereka, proses tumbuh kembang bahkan masa depan mereka (Astuti : 2009). Belajar adalah suatu proses usaha yang dilakukan seseorang untuk memperoleh suatu perubahan tingkah laku yang baru secara keseluruhan, sebagai hasil pengalamannya sendiri dalam interaksi dengan lingkungannya (Slameto, 2003). Sedangkan prestasi belajar adalah hasil yang dicapai oleh seseorang dalam usaha belajar sebagaimana yang dinyatakan dalam raport (Poerwanto, 1986).

Sebagai indikator kesehatan 2010, WHO telah menetapkan status kesehatan gigi dan mulut pada anak usia 12 tahun adalah DMF-T : $\leq 2$, OHI-S : $\leq 1,2$. Sedangkan di Jakarta, 90\% anak mengalami masalah gigi berlubang dan $80 \%$ menderita penyakit gusi. Angka itu diduga lebih parah di daerah serta anak-anak dari golongan ekonomi menengah ke bawah (Astuti : 2009). Dengan study pendahuluan yang telah dilakukan peneliti bahwa SDN Pagejugan 01 Brebes terletak di daerah desa dan jauh dari fasilitas kesehatan dan rata-rata anak dari golongan ekonomi menengah ke bawah. Selain itu mempunyai nilai rata-rata 68. Sedangkan SDN 03 Brebes merupakan SD yang terletak di daerah kota, di dukung dengan fasilitas kesehatan dan rata-rata anak dari golongan menengah ke atas. Selain itu mempunyai nilai rata-rata 75. Dengan data tersebut di atas maka peneliti inginmelakukan penelitian di SDN Pagejugan 01 Brebes dan SDN 03 Brebes.

Tujuan Penelitian ini adalah untuk mengetahui adanya hubungan Nilai DMF-T terhadap prestasi belajar antara SDN Pagejugan 01 dengan SDN 03 Brebes di kabupaten Brebes.

\section{METODE PENELITIAN}

Untuk mengetahui nilai DMF-T pada siswa SDN Pagejugan 01 Brebes dan SDN 03 Brebes, menggunakan jenis penelitian diskriptif kuantitatif yaitu bukan hanya mendeskripsikan tetapi untuk mengetahui pengaruh variabel bebas terhadap terikat.

Pengumpulan data diperoleh dengan cara observasi yaitu pengamatan yang dilakukan untuk mencari data primer secara langsung kelapangan dan data sekunder yang didapat dari data SD. Sedangkan metode yang digunakan dalam penelitian ini adalah cross sectional dimana penelitian mengambil data dalam waktu yang relative singkat. Populasi pada penelitian ini adalah siswa 
SDN Pagejugan 01 Brebes dan SDN 03 Brebes dengan jumlah 896 siswa.

Penelitian ini mengambil sampel 23\% dari populasi yaitu sebanyak 209 siswa dari kelas IV, V dan VI, yaitu 90 siswa SDN Pagejugan 01 Brebes dan 119 siswa SDN 03 Brebes.

Prosedur pelaksanaan penelitian yang dilakukan oleh peneliti untuk memperoleh data dalam penelitian ini adalah : Persiapan dengan mengajukan permohonan ijin ke kepala sekolah yang bersangkutan kemudian menyiapkan data identitas responden,melakukan kalibrasi dengan teman mahasiswa JKG, menyiapkan alat dan bahan, yaitu : diagnostic set, kapas, alkohol $70 \%$, alat tulis dan kartu status.Menyiapkan tempat penelitian untuk melakukan pemeriksaan DMF-T. Persiapan sampel dengan menempatkan sampel di lokasi yang telah disediakan. Memberikan pengarahan kepada sampel sebelum dilakukan penelitian.

Peneliti memeriksa keadaan kesehatan gigi sampel untuk mendapatkan nilai DMF-T pada bulan Juli tahun 2009. Kemudian memasukkan ke dalam kartu status dan menghitung nilai DMF-T. Dalam penelitian ini metode analisis data yang digunakan adalah diskriptif kuantitatif yaitu mendeskripsikan atau membuat gambaran dari hasil penelitian kemudian diolah, dibuat tabel, dihitung nilai dan dibuat prosentasi (presentase tabulasi).

\section{HASIL DAN PEMBAHASAN}

Penelitian dilakukan mengenai hubungan nilai DMF-T terhadap prestasi belajar antara SDN Pagejugan 01 dan SDN 03 Brebes dengan jumlah masing-masing responden 119 siswa SDN 03 Brebes dan 90 siswa SDN Pagejugan 01 Brebes di peroleh data nilai DMF-T dan rata-rata nilai dari empat semester sebelumnya. Adapun hasil penelitian yang diperoleh adalah sebagai berikut :
Tabel 1. Tabulasi silang DMF-T dan Prestasi Belajar pada siswa SDN 03 Brebes

\begin{tabular}{|c|c|c|c|c|c|c|c|c|c|c|c|c|}
\hline \multirow{3}{*}{ DMF-T } & \multicolumn{10}{|c|}{ Prestasi Belajar } & & \\
\hline & \multicolumn{2}{|c|}{$\begin{array}{c}\text { Baik } \\
\text { Sekali }\end{array}$} & \multicolumn{2}{|c|}{ Baik } & \multicolumn{2}{|c|}{ Cukup } & \multicolumn{2}{|c|}{ Kurang } & \multicolumn{2}{|c|}{$\begin{array}{c}\text { Kurang } \\
\text { Sekali }\end{array}$} & \multicolumn{2}{|c|}{ Total } \\
\hline & $\mathrm{n}$ & $\%$ & $\mathrm{n}$ & $\%$ & $\mathrm{n}$ & $\%$ & $\mathrm{n}$ & $\%$ & $\mathrm{n}$ & $\%$ & $\mathrm{n}$ & $\%$ \\
\hline $\begin{array}{l}\text { Sangat } \\
\text { Rendah }\end{array}$ & 3 & 2,5 & 79 & 66,3 & 12 & 3,4 & 0 & 0 & 0 & 0 & 94 & 79 \\
\hline Rendah & 1 & 0,8 & 19 & 16 & 0 & 0 & 0 & 0 & 0 & 0 & 20 & 16,8 \\
\hline Sedang & 0 & 0 & 4 & 3,4 & 1 & 0,8 & 0 & 0 & 0 & 0 & 5 & 4,2 \\
\hline Tinggi & 0 & 0 & 0 & 0 & 0 & 0 & 0 & 0 & 0 & 0 & 0 & 0 \\
\hline $\begin{array}{l}\text { Sangat } \\
\text { Tinggi }\end{array}$ & 0 & 0 & 0 & 0 & 0 & 0 & 0 & 0 & 0 & 0 & 0 & 0 \\
\hline Total & 4 & 3,3 & 102 & 85,7 & 13 & 10,9 & 0 & 0 & 0 & 0 & 119 & 100 \\
\hline
\end{tabular}

Responden dengan DMF-T sangat rendah dan mempunyai prestasi belajar yang baik sebanyak 79 siswa $(66,3 \%)$, selain itu DMF-T rendah dengan prestasi baik sebanyak 19 siswa (16\%) dan DMF-T sedang dengan prestasi belajar yang baik pula sebanyak 4 siswa $(3,4 \%)$. Hal ini dapat diartikan bahwa pada SDN 03 Brebes cenderung ada hubungan nilai DMF-T terhadap prestasi belajar siswa.

Tabel 2. Tabulasi Silang DMF-T dan Prestasi

Belajar pada Siswa SDN Pagejugan 01 Brebes

\begin{tabular}{|c|c|c|c|c|c|c|c|c|c|c|c|c|}
\hline \multirow{3}{*}{ DMF-T } & \multicolumn{10}{|c|}{ Prestasi Belajar } & & \\
\hline & \multicolumn{2}{|c|}{$\begin{array}{c}\text { Baik } \\
\text { Sekali }\end{array}$} & \multicolumn{2}{|c|}{ Baik } & \multicolumn{2}{|c|}{ Cukup } & \multicolumn{2}{|c|}{ Kurang } & \multicolumn{2}{|c|}{$\begin{array}{c}\text { Kurang } \\
\text { Sekali }\end{array}$} & \multicolumn{2}{|c|}{ Total } \\
\hline & $\mathrm{n}$ & $\%$ & $\mathrm{n}$ & $\%$ & $\mathrm{n}$ & $\%$ & $\mathrm{n}$ & $\%$ & $\mathrm{n}$ & $\%$ & $\mathrm{n}$ & $\%$ \\
\hline $\begin{array}{l}\text { Sangat } \\
\text { Rendah }\end{array}$ & 0 & 0 & 22 & 24,4 & 29 & 32,2 & 0 & 0 & 0 & 0 & 51 & 56,7 \\
\hline Rendah & 0 & 0 & 5 & 5,6 & 15 & 16,7 & 0 & 0 & 0 & 0 & 20 & 22,2 \\
\hline Sedang & 0 & 0 & 6 & 6,7 & 13 & 14,4 & 0 & 0 & 0 & 0 & 19 & 21,1 \\
\hline Tinggi & 0 & 0 & 0 & 0 & 0 & 0 & 0 & 0 & 0 & 0 & 0 & 0 \\
\hline $\begin{array}{l}\text { Sangat } \\
\text { Tinggi }\end{array}$ & 0 & 0 & 0 & 0 & 0 & 0 & 0 & 0 & 0 & 0 & 0 & 0 \\
\hline Total & 0 & 0 & 33 & 36,7 & 57 & 63,3 & 0 & 0 & 0 & 0 & 90 & 100 \\
\hline
\end{tabular}

Responden dengan DMF-T sangat rendah dengan prestasi cukup sebanyak 29 siswa $(32,2 \%)$, selain itu DMF-T rendah dengan prestasi cukup sebanyak 15 siswa $(16,7 \%)$ dan DMF-T sedang dengan prestasi belajar yang cukup sebanyak 13 siswa $(14,4 \%)$. Hal ini dapat diartikan bahwa pada SDN Pagejugan 01 Brebes cenderung tidak 
ada hubungan nilai DMF-T terhadap prestasi belajar.

Pada Tabel 1 dapat diketahui bahwa sebagian besar siswa yang mempunyai ratarata nilai prestasi belajar baik, juga mempunyai nilai DMF-T dengan kriteria sangat rendah yaitu sebanyak 79 responden $(66,3 \%)$. Hal ini dapat diartikan bahwa pada SDN 03 Brebes cenderung ada hubungan nilai DMF-T terhadap prestasi belajar siswa. Anak dengan gigi sehat tentu dapat mengunyah makanan dengan baik tanpa gangguan. Dengan demikian selera makanan tidak terganggu dan anak dapat menikmati makanannya. Jika giginya terasa sakit atau terdapat karies, umumnya anak akan menolak atau susah makan. Akibatnya dapat mengganggu atau mengurangi asupan gizi yang seharusnya dapat diterima tubuh anak, asupan gizi sangat mempengaruhi perkembangan otaknya. Dengan asupan gizi yang cukup, otak anak berkembang dengan baik sehingga menjadi anak yang berprestasi (Afrilina, 2006).

Sedangkan pada Tabel 2 dapat diketahui bahwa sebagian besar siswa yang mempunyai rata-rata nilai prestasi belajar cukup, mempunyai nilai DMF-T dengan kriteria sangat rendah yaitu sebanyak 29 responden $(32,2 \%)$, sehingga dapat diartikan bahwa pada SDN Pagejugan 01 Brebes cenderung tidak ada hubungan nilai DMF-T terhadap prestasi belajar. Hal ini disebabkan karena bukan hanya faktor DMF-T saja yang mempengaruhi prestasi belajar, tetapi ada beberapa faktor yang lebih berpengaruh terhadap prestasi belajar siswa. Salah satunya adalah lingkungan keluarga yang berpengaruh terhadap keberhasilan belajar siswa. Pengaruh pertama dan utama bagi kehidupan, pertumbuhan dan perkembangan seseorang adalah keluarga. Banyak waktu dan kesempatan bagi anak untuk berjumpa dan berinteraksi dengan keluarga. Perjumpaan dan interaksi tersebut sangat besar pengaruhnya bagi perilaku dan prestasi seseorang (Tu'u, 2004). Sedangkan kebanyakan para orangtua menyerahkan sepenuhnya pendidikan anaknya pada sekolah, demikian juga yang terjadi pada orangtua siswa SDN Pagejugan 01 Brebes. Hal ini disebabkan karena kurangnya perhatian masyarakat desa terhadap pendidikan anaknya. Padahal seharusnya orangtua memberikan perhatian dan semangat belajar yang lebih, karena waktu di rumah lebih banyak daripada di sekolah.

Selain itu faktor eksternal yang dapat mempengaruhi prestasi belajar siswa adalah faktor metode pembelajaran. Selain siswa, unsur terpenting yang ada dalam kegiatan pembelajaran adalah guru. Guru sebagai pengajar yang memberikan ilmu pengetahuan sekaligus pendidik yang mengajarkan nilai-nilai, akhlak, moral maupun sosial dan untuk menjalankan peran tersebut seorang guru dituntut untuk memiliki pengetahuan dan wawasan yang luas yang nantinya akan diajarkan kepada siswa. Seorang guru dalam menyampaikan materi perlu memilih metode mana yang sesuai dengan keadaan kelas atau siswa sehingga siswa merasa tertarik untuk mengikuti pelajaran yang diajarkan. Variasi metode dapat meningkatkan kegiatan belajar siswa (Slameto, 2003). Sedangkan pada SDN Pagejugan 01 Brebes, karena merupakan SD yang terletak di desa, jadi metode pembelajarannya masih konvensional.

\section{KESIMPULAN}

Berdasarkan hasil penelitian yang telah dilakukan, disimpulkan sebagai berikut :

1. Rata-rata nilai DMF-T SDN 03 Brebes adalah 0,7 dengan kriteria sangat rendah.

2. Rata-rata nilai DMF-T SDN Pagejugan 01 Brebes adalah 1,4 dengan kriteria rendah.

3. Rata-rata prestasi belajar siswa SDN 03 Brebes adalah 76,78 dengan kriteria baik.

4. Rata-rata prestasi belajar siswa SDN Pagejugan 01 Brebes adalah 68,46 dengan kriteria cukup.

5. Ada kecenderungan hubungan nilai DMF-T dan prestasi belajar siswa SDN 03 Brebes. Sedangkan tidak ada 
kecenderungan hubungan nilai DMF-T dan prestasi belajar siswa SDN Pagejugan 01 Brebes.

\section{DAFTAR PUSTAKA}

Afrilina, C. 2006. 75 Masalah Gigi Anak dan Solusinya. Jakarta : Kelompok Gramedia.

Arikunto, S. 2002. Prosedur Penelitian : Suatu Pendekatan Praktis. Jakarta: Rineka Cipta.

Astuti, T. 2009. 89\% Anak Derita Penyakit Gigi dan Mulut. http://www.depkes.go.id/index.php?op tion $=$ articles \& task $=$ viewarticle $\&$ artid $=$ 323\&Itemid=3. 18 Juni 2009

Depdiknas. 2006. ModelPenilaianKelasKurikulum Tingkat SatuanPaendidikan. Jakarta : Dharma Bhakti.

Depkes RI. 1993. PedomanPenyelenggaraanUpayaPela yananKesehatan Gigi di Puskesmas. Jakarta.

1995. Materi Tentang Kesehatan Untuk Guru UKS. Jakarta.

1996. Pendidikan Kesehatan Gigi. Bandung.

1999. Profil Kesehatan Gigi dan Mulut di Indonesia Pada Pelita VI. Jakarta.

- 2000. Pedoman Upaya Pelayanan Kesehatan Gigi dan Mulut di Puskesmas. Jakarta.

Hasbullah. 1994. KegiatanBelajar dan Prestasi. http://www.google.com. 29 April 2008.
Kartono. 1995. Kegiatan Belajar dan Prestasi. http://www.google.com. 29 April 2008.

Muhariani, I. 2008. Laporan Akhir Kepaniteraan Klinik Bagian Ilmu Kedokteran Gigi Pencegahan dan Kesehatan Gigi Masyarakat. http://www.google.com. 2008.

Nasution. 1995. KegiatanBelajar dan Prestasi. http://www.google.com. 29 April 2008.

Notoatmojo, S. 2002. Metodologi Penelitian Kesehatan. Jakarta: Rineka Cipta.

Nurhayati. 2004. Faktor-Faktor yang Mempengaruhi Pemanfaatan Waktu Luang Siswa dan Pengaruhnya terhadap Prestasi Belajar. http://www.google.com. 15 september 2007.

Pine. 1997. Makalah : Indeks def-t dan DMF-T Masyarakat Desa Cipondoh dan Desa Mekarsari Kecamatan Tirtamulya Kabupaten Karawang. http://www.google.com. 2008.

Poerwanto. 1986. KegiatanBelajar dan Prestasi. http://www.google.com. 29 April 2008.

Pratiwi, D. 2007. Gigi Sehat : Merawat Gigi Sehari-hari. Jakarta : Kompas

RPJPN. 2005. Undang-Undang Tentang Rencana Pembangunan Jangka Panjang Nasional Tahun 2005-2025. http://www.google.com.

Sardiman. 2006. Pengaruh Motivasi dan Metode Pembelajaran Terhadap Prestasi Belajar Akutansi Pada Siswa Kelas XI Ilmu Sosial SMA Negeri 1. http://www.google.com. 19 Februari 2008. 
Slameto. 2003. Pengaruh Motivasi dan Metode Pembelajaran Terhadap Prestasi Belajar Akutansi Pada Siswa Kelas XI Ilmu Sosial SMA Negeri 1. http://www.google.com. 19 Februari 2008.

2003. Pengertian : Prestasi Belajar. http://www.google.com. 5 Januari 2009.

Tarigan, R. 1990. Karies Gigi. Jakarta : Hipokrates.

Tu'u. 2004. Pengaruh Motivasi dan Metode Pembelajaran Terhadap Prestasi Belajar Akutansi Pada Siswa Kelas XI Ilmu Sosial SMA Negeri 1. http://www.google.com. 19 Februari 2008.

Winkel. 1996. Pengertian : Prestasi Belajar. http://www.google.com. 5 Januari 2009. 